\title{
PECULIARITIES OF CELLULAR, HUMORAL LINKS OF IMMUNITY AND DYNAMICS OF IMMUNOGLOBULINS IN COMMUNITY- ACQUIRED PNEUMONIA IN ADULTS AND THEIR IMPORTANCE FOR DIAGNOSTICS AND PROGNOSIS OF THE DISEASE
}

\author{
Vladyslav Bereznyakov, Oleksiy Korzh, Sergiy Krasnokutskiy
}

\begin{abstract}
The aim of our work was to study the characteristics of the immune status based on the analysis of the cellular, humoral links of immunity and dynamics of immunoglobulins in adults with community-acquired pneumonia (CAP), and their importance in the pathogenesis and prognosis of the disease.

Materials and methods. The study was carried out in the period 2017-2020 on the basis of the therapeutic department of the Municipal non-profit enterprise “City Clinical Multidisciplinary Hospital № 25” of Kharkiv City Council. The study involved 20 adult patients with CAP aged 18 to 80 years (mean age 36.5 10.3 ). The control group consisted of

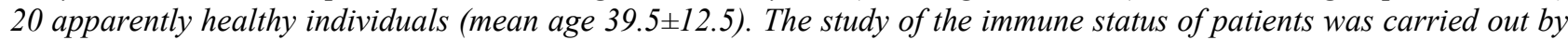
determining the phagocytic index, the content of lymphocytes, CD3+,CD4+,CD8+,CD16+,CD20+ and the level of immunoglobulins of classes $A, G, M$ in the dynamics of the disease: on the first and tenth days after hospitalization.

Results. On the first day of hospitalization, there was a significant imbalance in phagocytosis, T-and B-links of immunity. On the tenth day of treatment, the phagocytic index, the number of CD3+,CD4+, CD8+, CD16+ and CD20+ increased. An increase in Ig M, a decrease in Ig A and Ig $G$ were also noted. Thus, standard therapy for patients with CAP leads to its clinical and radiological resolution, but is not accompanied by the normalization of immunity parameters.

Conclusions. The features of immune disorders in patients with CAP were revealed: pneumonia increases the imbalance in the cellular link of immunity, the level of CD3+ and CD4+ decreases, there is no dynamics of the relative amount of $\mathrm{CD} 20+$. There are no significant changes in the humoral link of the immune status. For the treatment of patients with CAP, in addition to standard pharmacotherapy, it is necessary to include drugs that stimulate the immune system
\end{abstract}

Keywords: community-acquired pneumonia, pathogenesis, immunity: cellular and humoral, immunoglobulins, cytokines, inflammation, diagnosis

(C) The Author(s) 2021

This is an open access article under the Creative Commons CC BY license

\section{How to cite:}

Bereznyakov, V., Korzh, O., Krasnokutskiy, S. (2021). Peculiarities of cellular, humoral links of immunity and dynamics of immunoglobulins in community-acquired pneumonia in adults and their importance for diagnostics and prognosis the disease. ScienceRise: Medical Science, 4 (43), 1316. doi: http://doi.org/10.15587/2519-4798.2021.237712

\section{Introduction}

Currently, pneumonia ranks $4-5$ in the world in the structure of causes of death after cardiovascular and cancer diseases, cerebrovascular pathology, injuries and poisonings, and among infectious diseases take 1st place [1]. The mortality of hospitalized patients with severe disease ranges from 14 to $40 \%$ and increases among patients older than 60 years [2]. One of the leading causes of complicated and prolonged pneumonia is currently a change in the immunological reactivity of the organism [3]. However, the nature of immune disorders at certain stages of the inflammatory process, the factors of intercellular interaction are insufficiently studied and interpreted ambiguously. In this regard, it is of interest to study cytokines that act as mediators of the immune system. They regulate the strength, duration of the immune response and the nature of the inflammatory process, providing positive and negative immunoregulation [3]. In lung diseases, cytokines are involved in the infectious- inflammatory process and the allergic response at the level of the actual immune mechanisms and the effector link, largely determining the direction, severity and outcome of the pathological process $[4,5]$.

That is why the search for new criteria that determine the degree and nature of the immunological response in CAP is relevant and one of the priority areas of research.

The aim of the research was to study the features of the immune state based on the analysis of cellular and humoral immune components and the dynamics of immunoglobulins in adults with community-acquired pneumonia, and their importance in the pathogenesis and prognosis of the disease.

\section{Materials and methods}

The study was conducted in the period 2017-2020 on the basis of the therapeutic department of the Municipal non-profit enterprise "City Multidisciplinary Hospital 
No. 25" of the Kharkiv City Council. The study involved 20 adult patients with CAP aged 18 to 80 years (mean age $36.5 \pm 10.3$ years). The diagnosis of CAP was established on the basis of epidemiological, clinical, laboratory, radiological data. Patients with such pathologies as tuberculosis, bronchial asthma, hepatitis B, C and D, HIV, blood diseases and oncological diseases were excluded from the examination.

The control group was formed of 20 apparently healthy people (AHP), which is comparable with patients by age (mean age $39.5 \pm 12.5$ years) and sex.

Patients were examined according to Medical Standards (National Institute of Tuberculosis and Pulmonology named after F. G. Yanovsky).

The study was conducted in accordance with the requirements of the Helsinki Declaration of the World Medical Association, the Council of Europe Convention on Human Rights and Biomedicine, Good Clinical Practice (GCP) and approved by the Bioethics Commission of Kharkiv Medical Academy of Postgraduate Education (Protocol \# 4 of 20.04.2017). Patients who participated were included in the study after signing the informed consent.

Verification of CAP pathogens was performed using microscopic and bacteriological methods. Etiological diagnosis of atypical CAP pathogens included enzymelinked immunosorbent assay (a set of reagents JSC "Vector-Best-Ukraine") using the method of latex agglutination to detect bacterial antigen and/or antibodies to the pathogen. At hospitalization, all subjects, in accordance with the standards of the International Society of Pulmonologists and the Recommendations of the National Institute of Tuberculosis and Pulmonology named after F. G. Yanovsky (Kyiv, 2019), were prescribed standard antibacterial therapy.

The study of the immune status of patients was performed by determining the phagocytic index, lymphocyte content, CD3 + (T-lymphocytes), CD4 + (Thelpers), CD8 + (T-suppressors), CD16 + (zero cells), $\mathrm{CD} 20+$ (B-lymphocytes) in the serum method immunofluorescence with monoclonal antibodies [5] (used BD FACSCalibur cytofluorimeter and reagents from BD Biosciences, USA) and the level of immunoglobulins of classes A, G, M by radial immunodiffusion in agar by
Mancini G. et al. [6] (after incubation, the diameters of the precipitation rings were measured with a measuring instrument (binocular magnifier, eyepiece micrometer, ruler, magnifier) and the amount of immunoglobulins was determined from the calibration curve. BD Biosciences reagents, USA were also used for this purpose) in the dynamics of the disease: on the first and 10th day after hospitalization.

Statistical processing of the obtained data was performed using the software package Statistica for Windows 8.0 using Student's t-test. The results were considered reliable at $\mathrm{p}<0.05$ [7].

\section{Research results}

In the study of cellular immunity in patients with CAP, significant violations of immune status at the beginning of the disease compared with similar indicators of the AHP group. These changes were manifested by suppression of the activity of the T-cell immune system, phagocytosis and disruption of the Bcell link (Table 1).

In the analysis of immunity in patients with CAP, at the beginning of the disease (on the 1st day of hospitalization) found a significant decrease in phagocytic index $(39.0 \pm 0.9 \%, \mathrm{p}<0.001), \mathrm{CD} 3+(40.6 \pm 1.2, \mathrm{p}<0.05)$, $\mathrm{CD} 4+(22.5 \pm 1.5 \%, \mathrm{p}<0.001)$ and $\mathrm{CD} 16+(10.2 \pm 0.5 \%$, $\mathrm{p}<0.05)$ in comparison with these indicators of the AHP group.

In the humoral immune system, patients on the 1 st day of hospitalization showed a significant increase in Ig $M$ levels, while the content of Ig A did not differ from the data of the AHP group. The Ig G content did not differ from that of AHP.

Therefore, on the 1st day of hospitalization there is a significant imbalance of phagocytosis, T- and B-links of immunity.

On the 10th day of treatment, the phagocytic index, CD4+ increased, however, the amount of $\mathrm{CD} 3+$, CD8+, CD16+ and also CD20+ significantly increased. When comparing the rates of patients with CAP with those of the AHP group, it was found that the phagocytic index and CD4+ content remained without dynamics, and the number of lymphocytes, CD3+, CD8+, CD16+ and CD20+ normalized.

Table 1

Indicators of cellular and humoral immunity in community-acquired pneumonia in adults $(\mathrm{n}=20)$

\begin{tabular}{|c|c|c|c|}
\hline \multirow[b]{2}{*}{ Immunological parameters } & \multirow[b]{2}{*}{$\begin{array}{l}\text { Almost healthy } \\
\text { people }(n=20)\end{array}$} & \multicolumn{2}{|c|}{ Patients suffering from CAP $(\mathrm{n}=20)$} \\
\hline & & $\begin{array}{l}\text { On the 1st day of hos- } \\
\text { pitalization }\end{array}$ & $\begin{array}{l}\text { On the 10th day of hos- } \\
\text { pitalization }\end{array}$ \\
\hline Lymphocytes, \% & $34.0 \pm 3.7$ & $32.8 \pm 1.1$ & $33.8 \pm 1.9$ \\
\hline CD3+ (T-lymphocytes), \% & $55.2 \pm 2.1$ & $40.6 \pm 1.2 *$ & $45.4 \pm 2.2 * / * *$ \\
\hline CD4+ (T-helpers), \% & $37.9 \pm 1.1$ & $22.5 \pm 1.5^{*}$ & $25.9 \pm 0.9 * / * *$ \\
\hline CD8+ (T-suppressors), \% & $22.5 \pm 0.8$ & $18.7 \pm 0.7 *$ & $20.1 \pm 0.6^{*}$ \\
\hline CD16+ (zero cells), \% & $13.1 \pm 0.7$ & $10.2 \pm 0.5^{*}$ & $11.3 \pm 0.6$ \\
\hline CD20+ (B-lymphocytes), \% & $20.3 \pm 0.8$ & $17.9 \pm 0.4^{*}$ & $18.7 \pm 0.7$ \\
\hline Phagocytic index, $\%$ & $57.2 \pm 1.3$ & $39.0 \pm 0.9 *$ & $43.3 \pm 1.8 * / * *$ \\
\hline $\operatorname{Ig} \mathrm{G}, \mathrm{g} / \mathrm{l}$ & $8.8 \pm 0.9$ & $5.0 \pm 0.6^{*}$ & $6.4 \pm 0.6^{*}$ \\
\hline $\operatorname{Ig} \mathrm{A}, \mathrm{g} / \mathrm{l}$ & $0.9 \pm 0.1$ & $0.7 \pm 0.1$ & $0.9 \pm 0.1$ \\
\hline $\operatorname{Ig} \mathrm{M}, \mathrm{g} / 1$ & $1.1 \pm 0.1$ & $1.4 \pm 0.1 *$ & $1.1 \pm 0.1 * *$ \\
\hline
\end{tabular}

Note: *-compared with the AHP group ( $p<0.05) ; * *$ - compared with the indicators on the 1 st day of hospitalization $(p<0.05)$ 
Indicators of humoral immunity were much better, but complete normalization was not observed. In patients with CAP, on the 10th day of treatment, an increase in the concentration of Ig M (1.1 $\pm 0.1 \mathrm{~g} / \mathrm{l})$ was observed compared with the AHP group. There was also a tendency to decrease the content of $\operatorname{Ig} \mathrm{A}(0.9 \pm 0.1 \mathrm{~g} / \mathrm{l})$ and $\mathrm{Ig} \mathrm{G}(6.4 \pm 0.6 \mathrm{~g} / \mathrm{l})$.

Thus, the obtained data indicate that when using standard therapy for the treatment of CAP in adult patients, only improvements were observed, but most of them did not reach the data of the AHP group.

\section{Discussion of research results}

Analysis of clinical manifestations of CAP, depending on the severity, revealed more pronounced syndromes of intoxication and general inflammatory changes, clinical and radiological predominance of lung tissue lesions with pleural effusion syndrome, and in the auscultatory picture - moist small-bubble wheezing and crepitus.

The etiological structure of CAP according to the results of microbiological and enzyme-linked immunosorbent assay was as follows: pneumonia in patients with mild and moderate course was caused in most cases by intracellular pathogens, including Mycoplasma pneumoniae (30\%), gram-positive microflora - Streptococcus pneumoniae; in $25 \%$ of patients the pathogen was not identified. The leading pathogens of moderate pneumonia were Streptococcus pneumoniae $(40 \%)$ and mixed cultures of bacteria (20\%), with an increase in the proportion of Staphylococcus aureus (25\%), in addition, gram-negative pathogens $(15 \%)$ were detected.

Analysis of changes in cellular and humoral components of immunity in CAP was performed taking into account the severity. It was found that in patients with severe CAP was accompanied by an increase in the relative number of mature $\mathrm{T}$ lymphocytes (CD3+) with a decrease in their absolute value, a decrease in the number of T-helper inducers (CD4+) and an increase in cytotoxic (CD8+).

In the study of immunoglobulins in patients with CAP, the following data were obtained: the level of IgA tended to increase and the level of $\operatorname{IgM}$ to decrease, but the indicators did not differ statistically significantly from the level in AHP. IgG levels were significantly $(\mathrm{p}<0.05)$ reduced in patients with CAP.

The results of the analysis of the clinical course and etiological characteristics of CAP of the examined patients reflect the general trends of the disease, consistent with the literature $[1,3,8]$.

Indicators of the main classes of immunoglobulins in the initial period of CAP were characterized by lower values than in the AHP group, except for IgA. Dysimmunoglobulinemia on the background of the strengthening of immunocomplex mechanisms and functional insufficiency of the phagocytic unit revealed by us suggests the presence of immunocomplex and autoimmune components in the pathogenesis of complicated pneumonia.

Given the most important regulatory role of immunoglobulins $[4,9,10]$, we can assume insufficient intercellular activation of specific factors of the cellular immune system (indirectly confirmed by low T- and B-lymphocytes) in patients with severe disease, which leads to increased infectious process. Thus, in patients with severe CAP and a large amount of lung tissue damage, there is an imbalance of cellular and humoral immune systems, as well as immunoglobulins, which determines, in our opinion, the pathogenetic features of the disease.
Insufficiency of cellular and humoral mechanisms of immunity and imbalance of immunoglobulins in patients suffering from CAP, determines the severity of the disease.

Such changes may indicate a significant violation of immunological reactivity in patients with CAP. One of the mechanisms is a decrease in DNA synthesis, which reduces the rate of cell proliferation, inhibits the recognition of foreign antigens (reduced concentration of CD4+), which, in turn, leads to inhibition of growth and differentiation factors necessary for reproduction and maturation of B-lymphocytes, insignificant stimulation of growth and reproduction of cytotoxic and suppressor T-cells, slowing down of activation of macrophage system, decrease in immune tolerance, killer activity of zero cells $[4,11,12]$.

Study limitations. The article considers changes in the levels of cellular and humoral immune systems, as well as the dynamics of immunoglobulins in patients with CAP, using standard pharmacotherapy, however, no correlation analysis between these indicators.

Prospects for further research. The next stage of our study will be to study the production of cytokines in patients with CAP, in order to expand current ideas about the pathogenesis of CAP, its diagnosis and prognosis.

\section{Conclusions}

The peculiarities of immune disorders in patients with community-acquired pneumonia, which determine the severity of the disease and the volume of lung tissue inflammation.

The inflammatory process in the lungs exacerbates the imbalance in the cellular link of immunity, which is manifested in a more pronounced decrease in the number of total mature T-lymphocytes (CD3+) and T-lymphocytes-helpers (CD4+).

A distinctive feature of the cellular immune system in patients with community-acquired pneumonia is the lack of dynamics of the relative number of B-lymphocytes (CD20+).

In the humoral link of the general immune status of the body of patients with community-acquired pneumonia, significant $(p>0.05)$ changes do not occur.

The tendency to decrease immunoglobulins (Ig G and $\operatorname{Ig~M}$ ) causes severe and moderate course of community-acquired pneumonia and lung damage.

For the treatment of patients with communityacquired pneumonia, in addition to standard pharmacotherapy, it is necessary to include drugs that stimulate immunity.

The findings suggest the importance of studying the immune status of patients with community-acquired pneumonia, which will help develop new approaches to predicting the course of pneumonia, ways to correct metabolic disorders that develop in this condition, and will help identify risk groups for this pathology.

\section{Conflict of interests} interests.

The authors declare that they have no conflict of

\section{Financing}

The work is a fragment of the research "Mucoactive and herbal medicines for the treatment of cough in acute infectious and inflammatory diseases of the lower respiratory tract" (No. state registration 0117U000595). 


\section{References}

1. Eshwara, V., Mukhopadhyay, C., Rello, J. (2020). Community-acquired bacterial pneumonia in adults: An update. Indian Journal of Medical Research, 151 (4), 287-302. doi: http://doi.org/10.4103/ijmr.ijmr_1678_19

2. Lanks, C. W., Musani, A. I., Hsia, D. W. (2019). Community-acquired Pneumonia and Hospital-acquired Pneumonia. Medical Clinics of North America, 103 (3), 487-501. doi: http://doi.org/10.1016/j.mcna.2018.12.008

3. Huang, Y., Liu, A., Liang, L., Jiang, J., Luo, H., Deng, W. et. al. (2018). Diagnostic value of blood parameters for community-acquired pneumonia. International Immunopharmacology, 64, 10-15. doi: http://doi.org/10.1016/j.intimp.2018.08.022

4. Brands, X., Haak, B. W., Klarenbeek, A. M., Otto, N. A., Faber, D. R., Lutter, R. et. al. (2020). Concurrent Immune Suppression and Hyperinflammation in Patients With Community-Acquired Pneumonia. Frontiers in Immunology, 11. doi: http://doi.org/10.3389/fimmu.2020.00796

5. Ketlinskiy, S. A. (1999). Sovremennye aspekty izucheniya tsitokinov. Russian Journal of Immunology, 4 (1), 36-52.

6. Mancini, G., Carbonara, A. O., Heremans, J. F. (1965). Immunochemical quantitation of antigens by single radial immunodiffusion. Immunochemistry, 2 (3), 235-239. doi: http://doi.org/10.1016/0019-2791(65)90004-2

7. Lapach, S. N., Chubenko, A. B., Babych, P. N. (2001). Statystycheskye metodы v medyko-byolohycheskykh yssledovanyiakh s yspolzovanyem Exel. Kyiv: Moryon, 408.

8. Yu, Y., Fei, A. (2016). Atypical pathogen infection in community-acquired pneumonia. BioScience Trends, 10 (1), 7-13. doi: http://doi.org/10.5582/bst.2016.01021

9. Kolek, V., Jakubec, P., Losse, S. (2017). Diagnostics and treatment of community-acquired pneumonia - simplicity is the key to success. Vnitrni Lekarstvi, 63 (11), 770-775. doi: http://doi.org/10.36290/vnl.2017.148

10. Johnson, E. E., Wessling-Resnick, M. (2012). Iron metabolism and the innate immune response to infection. Microbes and Infection, 14 (3), 207-216. doi: http://doi.org/10.1016/j.micinf.2011.10.001

11. Nair, G. B., Niederman, M. S. (2021). Updates on community acquired pneumonia management in the ICU. Pharmacology \& Therapeutics, 217, 107663. doi: http://doi.org/10.1016/j.pharmthera.2020.107663

12. Cherayil, B. J. (2010). Iron and Immunity: Immunological Consequences of Iron Deficiency and Overload. Archivum Immunologiae et Therapiae Experimentalis, 58 (6), 407-415. doi: http://doi.org/10.1007/s00005-010-0095-9

Received date 16.06.2021

Accepted date 16.07.2021

Published date 30.07.2021

Vladyslav Bereznyakov*, PhD, Associate Professor, Department of General Practice - Family Medicine, Kharkiv Medical Academy of Postgraduate Education, Amosova str., 58, Kharkiv, Ukraine, 61176

Oleksiy Korzh, Doctor of Medical Sciences, Professor, Head of Department, Department of General Practice Family Medicine, Kharkiv Medical Academy of Postgraduate Education, Amosova str., 58, Kharkiv, Ukraine, 61176

Sergiy Krasnokutskiy, PhD, Associate Professor, Department of General Practice - Family Medicine, Kharkiv Medical Academy of Postgraduate Education, Amosova str., 58, Kharkiv, Ukraine, 61176

*Corresponding author: Vladyslav Bereznyakov, e-mail: nortaril@gmail.com 